\section{Colon sarcoidosis presenting with abdominal pain}

Sarcoidosis is a multisystemic disease of unknown cause that is diagnosed on the basis of the history and demonstration of granulomas in involved organs in patients before the age of 50 years; peak incidence occurs between the ages of 20 and 39 years [1]. The gastrointestinal tract is involved in less than $1 \%$ of all cases of sarcoidosis $[1,2]$. The stomach is the most commonly involved part of the gastrointestinal tract, but reported locations range from the esophagus to the rectum. Sarcoidosis is usually diagnosed incidentally [1-3].

The patient is a 36-year-old black woman born in the United States who presented with abdominal pain. She was well until approximately 3 weeks prior to admission when she had postumbilical hernia repair.

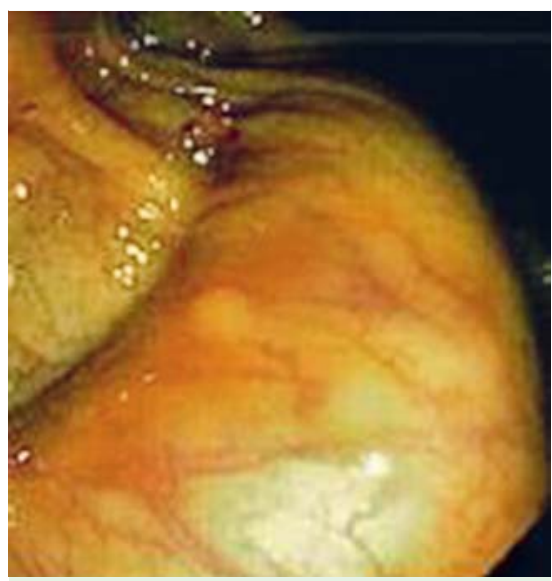

Fig. 1 Colonoscopic view of small sessile polyps throughout the colon.

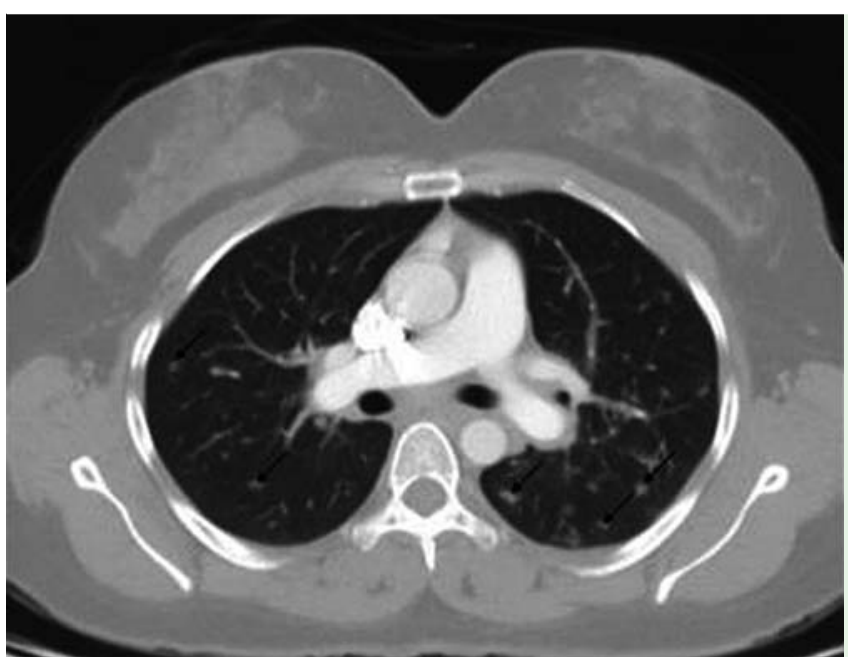

Three days before admission she experienced abdominal bloating, diarrhea, and severe abdominal pain. Her past medical history was positive for a diagnosis at another institution of inconsequential polyp disease. Her family history showed multiple family members with malignancy, but also family members with sarcoidosis, mostly cousins. On examination, the patient had marked tenderness on the periumbilical region and hyperactive bowel sounds but no peritoneal signs. Results of routine hematology and biochemistry investigations, including liver enzymes, were all within normal limits except for mild hyperkalemia. Abdominal computed tomography (CT) showed extensive retroperitoneal and mesenteric lymphadenopathy. Colonoscopy showed small sessile polyps throughout the colon ( Fig. 1). Colon random biopsy showed colonic mucosa with multifocal giant-cell and epithe-

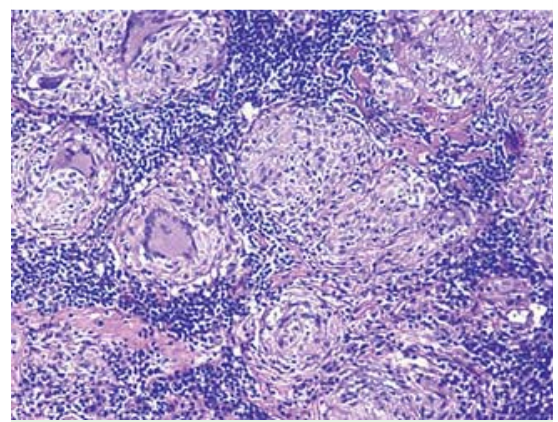

Fig. 2 Colon random biopsy showed colonic mucosa with multifocal giant-cell and epithe-

Fig. 3 Chest CT showed numerous nodules in both lungs with mild mediastinal and hilar adenopathy. lioid confluent granulomata. lioid confluent granulomata ( $\bullet$ Fig.2), suggestive of sarcoidosis. PAS and acidfast stains were negative for fungal and acid-fast organisms. Pankeratin stain was negative for metastatic carcinoma. Chest CT showed numerous nodules in both lungs with mild mediastinal and hilar adenopathy ( Fig.3). Right supraclavicular lymph node biopsy showed diffuse noncaseating granulomatous inflammation. Soft tissue CT of the neck showed scattered bilateral cervical lymphadenopathy with homogeneous enhancement suggesting reactive lymphadenopathy. Lymph nodes varied in size from 15 to $18 \mathrm{~mm}$.

Endoscopy_UCTN_Code_CCL_1AD_2AJ

\section{Competing interests: None}

Taha Bat ${ }^{1}$, Charles M. Morgan², Robert Marx ${ }^{3}$, Rebecca S. Bailey ${ }^{1}$

${ }^{1}$ Department of Internal Medicine, Northeastern Ohio University College of Medicine (NEOUCOM), Youngstown, Ohio, USA

2 Department of General Surgery, Northeastern Ohio University College of Medicine (NEOUCOM), Youngstown, Ohio, USA

${ }^{3}$ General Surgery, Northside Medical Center, Youngstown, Ohio, USA

\section{References}

1 Shigemitsu H, Saleh S, Sharma OP et al. Colon sarcoidosis responds to methotrexate: a case report with review of literature. J Pulm Respir Med 2013; 3: 148

2 Nunes H, Bouvry D, Soler $P$ et al. Sarcoidosis. Orphanet J Rare Dis 2007; 2: 46

3 Warshauer DM, Lee JKT. Imaging manifestations of abdominal sarcoidosis. AJR Am J Roentgenol 2004; 182: 15-28

\section{Bibliography}

DOI http://dx.doi.org/

10.1055/s-0034-1364890

Endoscopy 2014; 46: E121

(c) Georg Thieme Verlag KG

Stuttgart · New York

ISSN 0013-726X

\section{Corresponding author}

Taha Bat, MD

500 Gypsy Lane, Youngstown

$\mathrm{OH}$ 44505, USA

TAHA_BAT@vchs.net 